\title{
Harmonia: a MuseScore's plugin to teach music
}

\author{
João Teixeira Araújo, Rogério Tavares Constante, \\ Flávio Luiz Schiavoni, Octávio Deluchi \\ ${ }^{1}$ Arts Lab in Interfaces, Computers, and Everything Else - ALICE \\ Federal University of São João del-Rei - UFSJ \\ São João del-Rei - MG \\ teixeira.araujo@gmail.com, rogerio_constante@hotmail.com \\ fls@ufsj.edu.br, ocdeluchi@gmail.com
}

\begin{abstract}
Information and Communication Technologies (ICTs) have been characterized as a very effective resource for promoting innovation in the way of teaching and learning. In relation to the musical area, computer software of musical notation, like MuseScore, has been more and more used for the musical compositions and to teach and learn music writing, musical arrangement, composition and counterpoint. MuseScore is a free software that can easily be applied to academic purposes, such as universities, for teaching students in music fields and can also be used in the professional life of students who have graduated from courses that use it. In addition, it allows the implementation of plugins for various purposes, such as the analysis of scores in relation to various preset parameters. In this context, this work aims to present the development of the Harmonia, an open source plugin for MuseScore focused on teaching musical analysis and automatic verification of scores based in harmony predefined rules.
\end{abstract}

\section{Introduction}

Currently, we are in the era in which technological evolution is always present in our daily lives, which has brought changes in several areas, whether they are aimed at teaching or for the development of new tools. In general, the ways of teaching and learning a particular content have changed considerably over the time. The computer, for example, has been increasingly used, taking into account its ability to provide various functionalities in the form of implementation of computer programs intended for a multitude of purposes [1].

As digital technologies have become ubiquitous tools, being present in the daily lives of people in a very expressive way, it becomes very promising the use of these resources in the area of education. However, it is necessary to know how to manipulate such resources and use them strategically, with a focus on knowledge production, in a reflexive and creative way [2].

Among the areas that are promising for the use of new technologies is the education, and in particular, the music education. The new technologies have challenged musical education to undergo a series of transformations, challenging teachers to modify their respective educational concepts, didactic perspectives and to lead them to think about the new demands and possibilities regarding interactions with students [3].

This work presents the Harmonia plugin, an ex- tension of MuseScore focused on teaching and practicing music that aims to support the musician or student of music in the automatic analysis and verification of musical scores based on aspects frequently present in the study of harmony.

\section{Related tools on musical education}

Our work began with a survey of data on the educational tools aimed at the study of harmony until then. We focus on those software that perform the task of analyzing and investigating, from a score, the following aspects: voice leading; treatment of dissonances; melodic construction; texture and chord structure.

We used the following criteria to define what would be desirable in a tool to help automatic harmonic review. In the category voice leading, we chose the elements of 8th and 5th parallel, other parallel intervals, all voices in the same direction, hidden 8th and 5th, overlapping, cross relation, unison, the tendency tones. In dissonance treatment are the standards of suspension and passing note, as well as the treatment of the bass, in the 2nd inversion chord, among others. In melodic construction, we select the aspects augmented and diminished intervals, melodic leaps, definition of melodic contour through focal point, melodic variety and the extension of the melodies. In the texture category there are the issues of the spacing the voices and the vocal range. In chord structure, there are aspects of folding and omission of notes.

A first possibility that we considered to find musical tools to help students with harmony tasks was to find it in Moodle plugin database. Moodle[4] is a widely used learning management system that is extensible by the use of plugins. Searching for moodle plugins with the term "harmony" there were no plugins intended for this purpose. A search for the term "music" in the Moodle database led us to 4 plugins which did not fit our selection criteria.

Another possibility of tools could be to integrate musical analysis in a score notation tools. Since we intended to create an open source tool, we looked for an open source notation tool to base our research. We chose MuseScore, an open source score editor that also can be extended by plugins. In the MuseScore plugins, we found more than 70 plugins, but only two of them fitted our search criteria, highlighting the Check Harmony Rules plugin that verifies 3 aspects of the voice leading and 2 aspects of the melodic construction. 
We also verified 8 musical software, but only the Pizzicatto Composition Pro fitted the criteria defined by allowing the verification of 4 aspects of the voice leading, 2 aspects of the melodic construction, 1 aspect of the treatment of dissonances and 2 aspects of the texture.

\section{Harmonia plugin}

Due the lack of tools to meet this field of music teaching, we decided to create a plugin for MuseScore that would allow musical analysis based on the presented criteria. The pedagogical approach of the various aspects of the study of harmony is variable, according to the different authors, (like [5, 6], and others) and with the various teachinglearning proposals. A tool that performs verification based on fixed parameters in a given standard can be useful in a limited field of pedagogical approaches.

Our MuseScore plugin, called Harmonia, performs several checks of relevant musical aspects to the study of part writing exercises written in MuseScore, such as: voice leading, dissonance treatment, melodic construction, texture and chord structure. The configuration of the parameters of analysis and verification of the part writing exercises can be done directly in the plugin interface and recorded in a file for future use, in the various contexts.

Figure 1 demonstrates the Harmonia interface, divided into three main areas: the upper area, aimed at selecting which type of verification to execute, that could be under voice leading, dissonance treatment, melody, texture or chords; the center / left area, for selecting which parameters to verify under the selected verification type, such as dissonance use which are not a suspension pattern; and the area on the right, focused on selecting global parameters, such as the key to be checked.

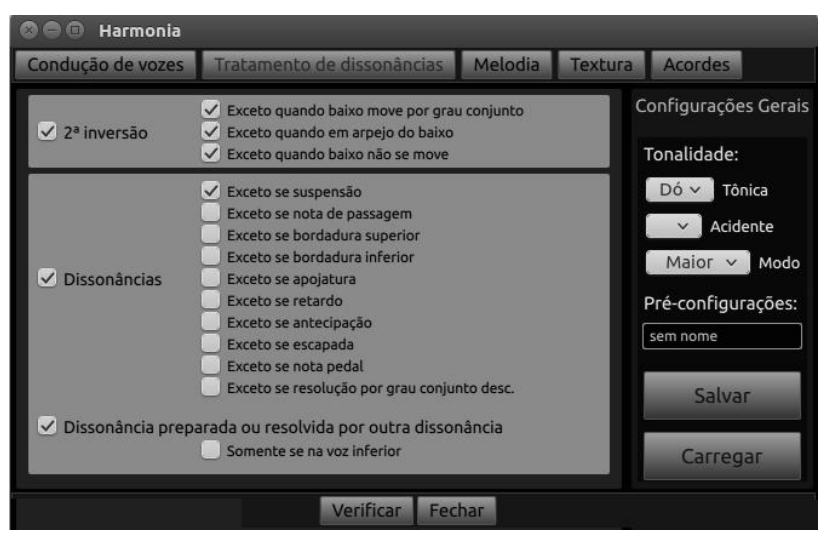

Figure 1: Example of the Harmonia's interface used to set up the tool

After the parsing process, the plugin lists a sequence of checked clickable items, indicating the type of scan and where the issues occurs (bars and voices). When clicked, the item is selected and the notes related to the respective problem become red. If desired, the user can continue clicking on the following items in the list to view them in the score. As the changes to the score are made to correct the issues detected, the list can be updated on the fly.

\section{Final considerations}

It is frequent in the teaching-learning process of harmony to perform a great amount of exercises, among which, those of part writing. The computational automation of the verification process of a great number of aspects, in the correction of exercises, leaves this activity more agile and fast. A student of music can have greater autonomy to seek solutions to issues detected by an automatic tool almost immediately, without having to wait for the teacher's analysis. Of course, it does not mean that the teacher will be expendable. The software verifies only a portion of the issues dealt with in the study of harmony, leaving aside so many aspects that are not objectively verifiable.

In this paper, we presented a tool to help students and teachers to automatically correct harmony phrases trying to give feedback on the fly for those who wants some help in musical writing like composition, arrangement and counterpoint. The presented plugin is moldable to meet the various pedagogical proposals, through the configuration of what is intended to be checked. This feature allows it to be used as a support tool in conjunction with different methods and reference textbooks of harmony.

We chose to write it as a plugin for the MuseScore since our purpose is consistent with the concept of FLOSS, especially considering its applicability in the academic field. Because it is a free software, MuseScore is a tool that can easily be applied in universities, since its cost is zero and from it, the student can learn to use it and consequently use it even in the future, in their professional life, without having to worry about copyright and other factors that the tools paid end up implying. In this way, the development of plugins for MuseScore, ends up being quite promising, since from them it is possible to implement several functionalities that sometimes a free tool does not have.

\section{Acknowledgments}

Authors would like to thanks to all ALICE members that made this research and development possible. The authors would like also to thank the support of the funding agencies CNPq and FAPEMIG.

\section{References}

[1] Ana Cristina Vieira Gouveia. Educação musical e as novas tecnologias. ferramentas de apoio ao docente de música. 2015.

[2] Luciano Luan Gomes Paiva. Tecnologias digitais na educação musical: discussões emergentes omunicação. XI Conferência Regional Latino-Americana de Educação Musical da ISME, 2017.

[3] Susana Ester Krüger. Educação musical apoiada pelas novas tecnologias de informação e comunicação (tic): pesquisas, práticas e formação de docentes. Revista da ABEM, 14(14), 2014.

[4] Martin Dougiamas and Peter Taylor. Moodle: Using learning communities to create an open source course management system. In EdMedia+ Innovate Learning, pages 171-178. Association for the Advancement of Computing in Education (AACE), 2003. 
[5] Arnold Schoenberg. Harmonia. Editora UNESP, São Paulo, SP, 2001.

[6] Stefan Kostka and Dorothy Payne. Tonal Harmony. Alfred A. Knopf, New York, 1984. 